\title{
UNIVERSAL MASKING DURING COVID-19 PANDEMIC - CURRENT EVIDENCE AND CONTROVERSIES
}

\author{
Mariana A. Quintana-Díaz ${ }^{1}$ and Carlos A. Aguilar-Salinas $2,3,4 *$ \\ ${ }^{1}$ Tecnológico de Monterrey, School of Medicine and Health Sciences, Guadalajara, Jal., Mexico; ${ }^{2}$ Metabolic \\ Diseases Research Unit, Nutrition Directorate, and ${ }^{3}$ Department of Endocrinology and Metabolism, Instituto \\ Nacional de Ciencias Médicas y Nutrición Salvador Zubirán, Mexico City, Mexico; ${ }^{4}$ Tecnológico de Monterrey, \\ School of Medicine and Health Sciences, Monterrey, NL, Mexico
}

\begin{abstract}
The emergence of coronavirus disease 19 pandemic and novel research on the high transmissibility of severe acute respiratory syndrome coronavirus 2 (SARS-CoV-2) has raised controversies over the use of face masks to prevent community transmission. Specific regulations need to be fulfilled to use a face mask as part of the personal protective equipment and high quality of evidence supporting its use to prevent respiratory viral infections, including SARS-CoV-2, is lacking. However, its widespread use is becoming a standard practice in some countries and discrepancies between health authorities on their policy have led to controversy. The aim of this review is to provide an outlook on recent research in this matter and areas of opportunity. (REV INVEST CLIN. 2020;72(3):144-50)
\end{abstract}

Key words: Face masks. Coronavirus disease 19 . Severe acute respiratory syndrome coronavirus 2. Universal masking. Pandemic.

\section{INTRODUCTION}

The widespread use of face masks is becoming a standard practice in some countries with the emergence of coronavirus disease 19 (COVID-19) pandemic. However, disagreements between health authorities on their policy have led to controversy within the medical community. Some recommendations are being made despite the lack of high quality of evidence to support the use of face masks as a preventive measure during this pandemic. A general outlook of recent research in this matter and areas of opportunity are discussed in this review.

\section{TYPES OF FACE MASKS AND REGULATIONS}

The types of masks currently available vary depending on the material, design, and purpose for which

Disclaimer: This manuscript has been accepted for publication and has undergone an exceptional internal review process to expedite its dissemination, as it contains urgent information of special interest regarding COVID-19.

*Corresponding author:

Carlos Alberto Aguilar-Salinas

E-mail: caguilarsalinas@yahoo.com
Received for publication: 01-05-2020

Approved for publication: 02-05-2020

DOI: $10.24875 / R I C .20000196$

0034-8376 / (c) 2020 Revista de Investigación Clínica. Published by Permanyer. This is an open access article under the CC BY-NC-ND license (http://creativecommons.org/licenses/by-nc-nd/4.0/). 
Table 1. Comparison between emergent respiratory viruses

\begin{tabular}{|c|c|c|c|c|}
\hline & $\begin{array}{l}\text { H1N1 } \\
(2009)\end{array}$ & $\begin{array}{l}\text { MERS-CoV } \\
\text { (2012) }\end{array}$ & $\begin{array}{l}\text { SARS-CoV1 } \\
(2002)\end{array}$ & $\begin{array}{l}\text { SARS-CoV2 } \\
(2019)\end{array}$ \\
\hline Disease & Influenza A & $\begin{array}{c}\text { Middle East respiratory } \\
\text { syndrome (MERS) }\end{array}$ & $\begin{array}{c}\text { Severe acute respiratory } \\
\text { syndrome (SARS) }\end{array}$ & $\begin{array}{l}\text { Coronavirus disease } \\
\text { (COVID-19) }\end{array}$ \\
\hline Confirmed cases & 100.5 million & 2494 & 8096 & $2,471,136^{*}$ \\
\hline $\begin{array}{l}\text { Human-to-human } \\
\text { transmission } \\
\text { (of relevance) }\end{array}$ & $\begin{array}{c}\text { Droplets > Aerosols } \\
\text { Contact Airborne }\end{array}$ & $\begin{array}{l}\text { Contact droplets > } \\
\text { Aerosols Airborne }\end{array}$ & $\begin{array}{c}\text { Aerosols > Droplets } \\
\text { Indirect Contact } \\
\text { Airborne }\end{array}$ & $\begin{array}{c}\text { Aerosols > Droplets } \\
\text { Indirect Contact** } \\
\text { Airborne** }\end{array}$ \\
\hline Incubation period (days) & $1-4$ & $4.5-5.2$ & $3.6-4.4$ & $2-15$ \\
\hline Reproductive number & $1.2-1.6$ & $<1$ & $2-5$ & $1.4-5.5^{* * *}$ \\
\hline Case fatality rate & $2 \%$ & $34.4 \%$ & $9.6 \%$ & $0.9-2.1 \% * * *$ \\
\hline
\end{tabular}

Droplets: $>5 \mu \mathrm{m}$; aerosols: $<5 \mu \mathrm{m}$.

*As of April 22, 2020.

**The importance is controversial, discussion on text.

***Estimates vary and depend on the number of confirmed cases; fatality rate is based on last estimates in Wuhan, China ${ }^{11}$.

they are made ${ }^{1}$. To be used in professional or healthcare settings, safety and health standards need to be fulfilled and these are regulated by specific agencies. In the United States and many parts of America by the Food and Drug Administration (FDA), the National Institute for Occupational Safety and Health (NIOSH), and the Occupational Safety and Health Administration (OSHA).

The terms face mask, medical mask, and surgical mask are often used interchangeably, but under standardized definitions, a face mask is not under industry regulation. Another difference to be considered is the one between a mask and a respirator, which is the ability of the latter to provide a reliable level of protection from large and small airborne particles. This varies depending on the filtration capability and is designated with a number, meaning that a N95 respirator filters at least $95 \%$ of airborne particles. Despite this difference, both the medical/surgical mask and the $\mathrm{N} 95$ respirator are tested for fluid resistance, filtration efficiency, flammability, and biocompatibility under the NIOSH and FDA regulations ${ }^{2}$. For the official definitions and regulations, Tables S1 and S2 in the Supplementary Appendix.

With the emergence of novel respiratory pathogens, much research has been done to explore the efficacy of face masks in filtering respiratory viruses or reducing their transmission and to be used for protection or prevention, respectively. Most of the studies have been done on influenza outbreaks and it has been concluded through systematic reviews and metaanalysis that there is limited evidence to support the use of masks in health care or community settings as prevention methods due to the heterogeneity of the studies and inconsistent methodology ${ }^{3}$. Nevertheless, this research has provided knowledge about the mode of transmission and led to the implementation of coordinated preventive measures, such as hand hygiene and social distancing.

\section{MECHANISMS OF VIRUS TRANSMISSION}

A comparison of severe acute respiratory syndrome coronavirus 2 (SARS-CoV-2) with three emergent respiratory viruses, two coronaviruses ( $\mathrm{CoV}$ ) and influenza virus, is summarized in table 1 . The data were collected from latest WHO and Center for Disease Control and Prevention (CDC) reports ${ }^{5-8}$ and from reviews ${ }^{9-11}$.

The most accepted and studied human-to-human transmission mechanisms of respiratory viruses are the droplet, airborne, and contact transmission (direct and indirect) routes ${ }^{9}$. Wells introduced the concept of emissions and proposed two categories: large and small droplets, based on the size and evaporation times $^{12}$. To date, droplets below a diameter of $5 \mu \mathrm{m}$ (micrometers) are known as aerosols or droplet nuclei, and those larger than $5 \mu \mathrm{m}$ are called spray 
droplets or simply droplets; although diameter values vary along the literature, the $5 \mu \mathrm{m}$ cutoff is currently recommended according to the WHO guidelines ${ }^{13}$. This classification system continues to be the reference for risk management, recommendations, and allocation of resources.

New experimental models of respiratory emissions have proposed that the rapid spread of SARS-CoV-2 might not be efficiently prevented following this droplet transmission pattern, suggesting that the present recommendations may underestimate the exposure range $^{14}$. These models propose that the trajectory of sneezes and coughs is multiphase, creating a turbulent cloud of respiratory emissions rather than a formation of droplets before ejection and that speaking also contributes to the release of numerous particles with a mean diameter of $1 \mu \mathrm{m}$ and interperson variability ${ }^{15,16}$.

The contact and airborne transmission routes appear to be viable for SARS-CoV-2 based on a recent experiment done by van Doremalen et al. They compared the stability between SARS-CoV-1 and SARSCoV-2 in five environmental media: aerosols, plastic, stainless steel, copper, and cardboard and found similar half-lives between the viruses in all conditions with exception of stainless steel and plastic, where SARS-CoV-2 had longer stability. These findings suggest that the epidemiological differences between these viruses might be due to other virulence factors ${ }^{17}$.

A series of investigations are trying to understand the high virulence of SARS-CoV-2 given the concern of the potential high transmissibility from asymptomatic patients. This began with reports of patients who had presumably acquired the disease during the incubation period ${ }^{18,19}$. A case series from two family clusters $^{20}$ found that the viral load of SARS-CoV-2 on nasal and throat swabs was similar between asymptomatic patients and symptomatic patients. Findings from Woelfel et al. ${ }^{21}$ suggest an active replication of SARS-CoV-2 in the nasopharynx, which might explain the positive tests in the prodromal stage and the risk of asymptomatic transmission.

All of these elements are important to be taken into account to understand that limiting the transmission of a virus, with the current concern on
SARS-CoV-2, in both health care and community settings, requires a coordinated approach. In the same way, when evaluating the outcomes of preventive measures, it becomes challenging to measure individual contributions.

\section{UNIVERSAL MASKING: DEFINITION, CONTROVERSIES, AND EVIDENCE}

There is not an official definition of the term universal masking but rather a recent and growing use on behalf of the general and medical community in reference to a widespread use of masks with the intention of preventing community transmission of COVID-1922. This has led to appeal health authorities to make decisions on the matter.

The latest WHO statement on the use of masks from April $^{23}$ expresses that "there is no evidence that wearing a mask (whether medical or other types) by healthy persons in the wider community setting can prevent infection from COVID-19" and does not make recommendations for or against their use. However, it is specified that if local policy-makers consider otherwise, they should define the purpose of use, risk of exposure, vulnerability of the user, setting, suitability, and type of mask to make a "risk-based approach."

Feng et al. compared the recommendations from different countries and found that while there is an agreement on reserving medical masks for healthcare personnel and symptomatic patients, discrepancies arise in community settings ${ }^{24}$. In China, South Korea, Japan, Hong Kong, Singapore, and Czech Republic, the widespread use of masks has been implemented. In some countries like China, it was enforced by the authorities and the type of mask recommended is based on risk stratification while others, such as Hong Kong and Taiwan, have reached this by "social advocacy." Health authorities in countries such as the UK and Germany have abstained from making recommendations in the absence of evidence. Something similar has happened in Mexico where the federal health ministry has not made official recommendations attending the use of cloth masks ${ }^{25}$. The CDC, on the other hand, updated their advice on April 4 and now recommends that people should wear homemade cloth masks in public areas and released instructions on how to make and wear them ${ }^{26}$. 
This discrepancy between health authorities and the lack of evidence has raised discussion within the medical community. Some authors propose the use of indirect evidence (inferred evidence from primary studies) to support the use of face masks until better evidence becomes available ${ }^{27}$. Nevertheless, clinical decisions based on indirectness require a complex analysis of prospectively collected data ${ }^{28}$. To complicate matters further, the problem is being addressed based on different populations (medical workers and community), interventions (medical masks and cloth masks), and outcomes (protection and source control). Therefore, a consensus becomes challenging when the clinical question is inconsistent.

In terms of protection, as mentioned earlier, much of the research has been done on influenza, and currently, there are no studies on SARS-CoV-2. A recent systematic review ${ }^{29}$ on the efficacy between medical masks and N95 respirators in preventing viral infection, including $\mathrm{CoV}$, found no increase of laboratory confirmed infections (odds ratio [OR] 1.06; 95\% confidence interval $[\mathrm{Cl}] 0.90-1.25$ ) or clinical respiratory illness (OR 1.49; 95\% Cl 0.98-2.28) with the use of medical mask compared to N95. However, none of the trials identified SARS-CoV-2 and the authors graded the overall studies as very low to low quality of evidence (GRADE).

When focusing on source control, which is the arising concern given the asymptomatic transmission of SARS-CoV-2, there are no randomized controlled trials evaluating the effectiveness of face masks on reducing the transmission of SARS-CoV-2 in neither health care nor community settings, but meta-analysis and systematic reviews have been conducted trying to answer this question.

Two systematic reviews ${ }^{30,31}$ did not find strong evidence to support the use of masks within the community as a protective measure during this pandemic; however, they are quick reviews and one of them has not been peer-reviewed ${ }^{30}$, which lowers their quality. An update $^{32}$ to a previously conducted systematic review on physical barriers as prevention measures done by Jefferson et al. in $2011^{33}$ found that the use of masks alone versus no masks ( 9 trials in health care workers and 7 in community) shows no significant reductions in influenza-like illness or in confirmed influenza infections, 7\% (relative risk [RR] $0.93 \mathrm{Cl}$ 95\% 0.83-1.05) and $16 \%$ (RR $0.84 \mathrm{Cl} 95 \%$ 0.61-1.17), respectively. They recommended the use of masks combined with other measures (social distancing), grading the studies on "variable quality of evidence." The 2011 review was the basis for the respiratory hygiene recommendations (use of medical masks and handwashing during respiratory infections) in the current $\mathrm{WHO}$ guidelines ${ }^{34}$ (very low quality of evidence [GRADE], strong consensus recommendation); however, the update has not been peer-reviewed to guide clinical practice ${ }^{35}$.

A recent trial on virus shedding in exhaled breath showed promising implications for this matter ${ }^{36}$. Leung et al. studied 111 patients with confirmed respiratory viral infection (seasonal coronavirus, influenza, and rhinovirus) and compared the viral load in respiratory droplets and aerosol samples with and without the use of a surgical mask. They found significant reductions in the detection of the CoV in both droplets $(30 \%-0 \%, p=0.09)$ and aerosols $(40 \%-0 \%$, $\mathrm{p}=0.04)$. However, since no SARS-CoV-2 was identified, the applicability of this study is uncertain.

So far, there is no high quality of evidence to demonstrate the effectiveness of medical masks in the community during this pandemic, neither as source control nor as protection. Some authors have pointed out that implementing the use of medical masks in the community would lead to shortage of personal protective equipment for the health-care personnel. This challenge is already happening in many countries. Therefore, focusing on the use of cloth masks appears to be more sustainable ${ }^{37}$. However, the same limitations arise since the effectiveness of cloth masks in community settings has not been tested. In health-care settings, a randomized trial ${ }^{38}$ showed that the use of cloth mask compared to medical masks had significantly higher rates of influenza-like illness (RR 13.25; 95\% Cl 1.74-100.97) and did not recommend its use. The authors discussed that moisture retention and reuse of the cloth masks may have contributed to those findings.

Some important aspects to be considered before encouraging the use of homemade cloth masks are outlined in an expert consultation review ${ }^{39}$. Two main elements would determine the potential effectiveness of a cloth mask: the mask itself and the wearer. Consequently, for a mask to adequately fulfill its function, other variables intervene such as the type of fabric 
Figure 1. Potential advantages and disadvantages on the use of face masks. Reproduced with permission from SlidesCarnival (https://www.slidescarnival.com).

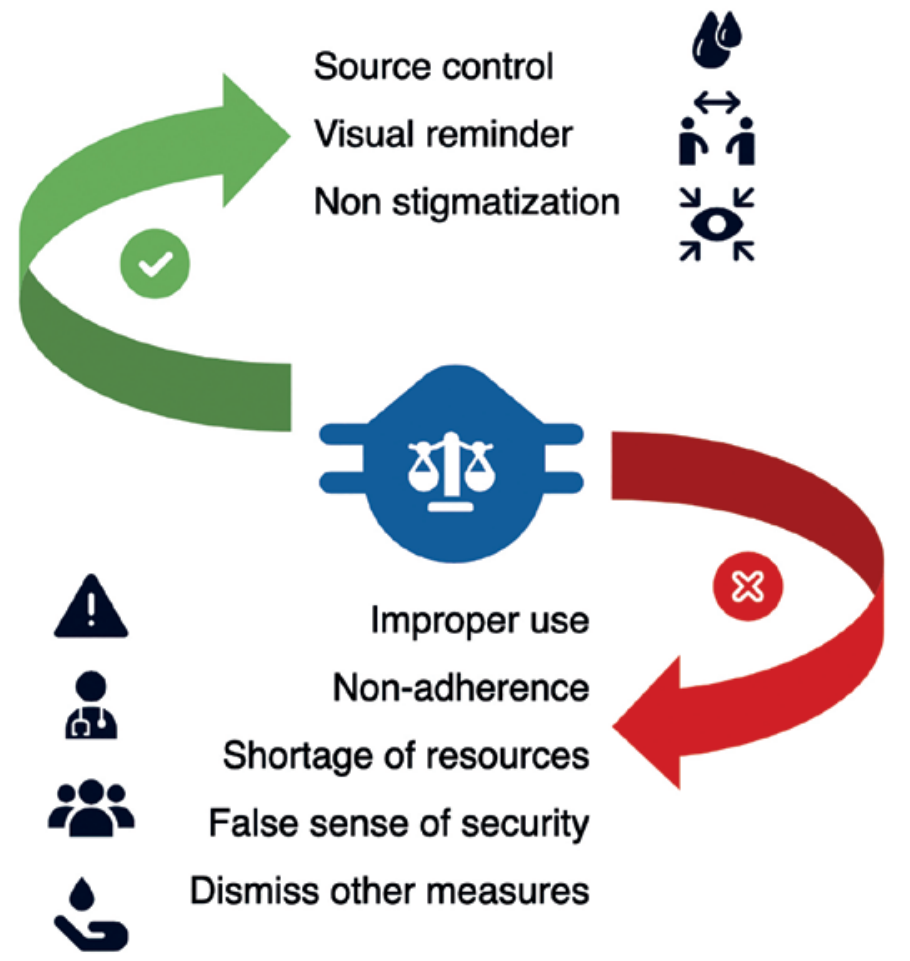

(woven or knitted), material (e.g., cotton or polyester), number of layers, and design. These variables will define its filtration efficacy (blockage of particles), leakage, and differential pressure (how much they difficult breathing) in a wide variation.

The filtration efficiency on various types of cloth masks has been tested using different size particles with ranges varying from $39 \%$ to $65 \%$ under laboratory conditions ${ }^{40}$ and $48 \%$ to $83 \%$ using different household materials ${ }^{41}$. A recent study ${ }^{42}$ aimed to evaluate the effectiveness of two-layered cotton masks compared to three-layered polypropylene surgical masks in filtering SARS-CoV-2 and found that both were ineffective in filtering the virus during coughs. However, this was a small study, which only included four symptomatic patients.

The role of the wearer is important since it determines how well and often they use the mask, the amount of moisture produced, and the breathing difficulty; where the last two are interrelated and depend on the type of fabric and differential pressure, respectively. Evidence from the past pandemics could indirectly estimate wearer's role, in which observations from the $\mathrm{H} 1 \mathrm{~N} 1$ pandemic found $<50 \%$ of mask adherence ${ }^{43}$. In addition, MacIntyre and Chughtai observed other determinants of compliance such as level of discomfort and reduced risk perception from SARS and influenza pandemics ${ }^{44}$.

Given the uncertainties of the filtering efficiency and the level of adherence during this pandemic, Howard et al. ${ }^{45}$ proposed an estimation of the impact of wearing masks on the reproductive number (RO). They used a model ${ }^{46}$ based on possibilities of a full range efficacy and a full range mask adherence at an estimated RO of 2.4 and suggest that on a $50 \%$ efficacy and $50 \%$ adherence, the Ro could go down to 1.35 , arguing that such reduction would be comparable to seasonal influenza ( $R O \approx 1.28$ ). However, even if SARS-CoV-2 could resemble the transmission dynamics of influenza, the estimates of the RO can vary depending on several factors, such as the population studied, other public health interventions, and surveillance intensity ${ }^{47}$.

To put if briefly, encouraging the use of masks, whether medical or cloth masks, without standardized instructions and adequate teaching, would result in a wide range of efficacy profiles with potential disadvantages that could outweigh the advantages in an uncertain degree (Fig. 1). 


\section{CONCLUSIONS}

Future investigations on the use of face masks within the community and their effectiveness, as well as cost-effectiveness studies, are needed to provide high quality of evidence to address these uncertainties and guide decisions. Randomized controlled studies performed at community levels are required to plan future public policies. The study samples should be stratified according to their risk profile (elders, health workers, inmates, etc.) and predefined outcomes should be prospectively assessed. The main challenge will be to capture the majority of the clinically relevant outcomes with enough precision.

\section{ACKNOWLEDGMENTS}

The authors would like to thank Heriberto Medina M.D. (Instituto Nacional de Ciencias Médicas y Nutrición Salvador Zubirán, Mexico City), Rafael Bravo, M.D. (Hospital Ángeles Lomas, Edo. Méx., Mexico), and Martha Parra, M.D. (Tecnológico de Monterrey, Mexico) for their comments on the final version of the manuscript. We also thank Karen Ruvalcaba (Tecnológico de Monterrey, Mexico) for her contribution in the preparation of the manuscript.

\section{REFERENCES}

1. Brown CK. Respiratory protection against emerging infectious diseases: face masks, respirators, and tools for choosing between them. Health Secur. 2019;17:133-9.

2. National Institute for Occupational Safety and Health. Types of respiratory protection. In: Hospital Respiratory Protection Program Toolkit. United States: National Institute for Occupational Safety and Health; 2015.

3. Bin-Reza F, Chavarrias VL, Nicoll A, Chamberland ME. The use of masks and respirators to prevent transmission of influenza: a systematic review of the scientific evidence. Influenza Other Respir Viruses. 2012;6:257-67.

4. Cowling BJ, Zhou Y, Ip DK, Leung GM, Aiello AE. Face masks to prevent transmission of influenza virus: a systematic review. Epidemiol Infect. 2010;138:449-56.

5. Centre for Disease Control and Prevention. The Burden of the Influenza A H1N1pdm09 Virus Since the 2009 Pandemic. Available from: https://www.cdc.gov/flu/pandemic-resources/burden-of-h1n1.html. [Last accesed on 2020 Apr 18]

6. World Health Organization. Summary of Probable SARS Cases with Onset of Illness; 2003. Available from: https://www.who. int/csr/sars/country/table2004_04_21/en. [Last accesed on 2020 Apr 18].

7. World Health Organization. Middle East Respiratory Syndrome Coronavirus (MERS-CoV). Available from: https://www.who.int/ emergencies/mers-cov/en. [Last accesed on 2020 Apr 18].

8. World Health Organization. COVID-19 Situation Report-93. 2020 Available from: https://www.who.int/docs/defaultsource/coronaviruse/situation-reports/20200422-sitrep93-covid-19.pdf?sfvrsn=35cf80d7 4. [Last accesed on 2020 Apr 22].
9. Otter J, Donskey C, Yezli S, Douthwaite S, Goldenberg S. Transmission of SARS and MERS coronaviruses and influenza virus in healthcare settings: the possible role of dry surface contamination. J Hosp Infect. 2016;92:235-50.

10. Xie M, Chen Q. Insight into 2019 novel coronavirus-an updated intrim review and lessons from SARS-CoV and MERS-CoV. J Infect Dis. 2020;94:119-24.

11. Wu JT, Leung K, Bushman M, Kishore N, Niehus R, de Salazar PM, et al. Estimating clinical severity of COVID-19 from the transmission dynamics in Wuhan, China. Nat Med. 2020; 26:506-10.

12. Duguid JP. The size and the duration of air-carriage of respiratory droplets and droplet-nuclei. J Hyg (Lond). 1946;44: 471-9.

13. World Health Organization. Droplet precautions. In: Infection Prevention and Control of Epidemic-and Pandemic-prone Acute Respiratory Infections in Health Care. Geneva: World Health Organization; 2014. p. 48-51.

14. Bourouiba L, Dehandschoewercker E, Bush JW. Violent expiratory events: on coughing and sneezing. J Fluid Mech. 2014; 745:537-63.

15. Scharfman BE, Techet AH, Bush JW, Bourouiba L. Visualization of sneeze ejecta: steps of fluid fragmentation leading to respiratory droplets. Exp Fluids. 2016;57:1-9.

16. Asadi S, Wexler AS, Cappa CD, Barreda S, Bouvier NM, Ristenpart WD. Aerosol emission and superemission during human speech increase with voice loudness. Sci Rep. 2019;9:1-10.

17. van Doremalen N, Bushmaker T, Morris DH, Holbrook MG, Gamble $\mathrm{A}$, Williamson $\mathrm{BN}$, et al. Aerosol and surface stability of SARS-CoV-2 as compared with SARS-CoV-1. N Engl J Med. 2020;382:1564-7

18. Rothe C, Schunk M, Sothmann P, Bretzel G, Froeschl G, Wallrauch C, et al. Transmission of 2019-NCOV infection from an asymptomatic contact in Germany. N Engl J Med. 2020; 382:970-1.

19. Bai Y, Yao L, Wei T, Tian F, Jin DY. Presumed asymptomatic carrier transmission of COVID-19. N Engl J Med. 2020;382: 1199-207.

20. Lirong Z. SARS-CoV-2 viral load in upper respiratory specimens of infected patients. N Engl J Med. 2020;382:1175-7.

21. Woelfel R, Corman VM, Guggemos W, Seilmaier M, Zange S, Mueller MA, et al. Virological Assessment of Hospitalized Cases of Coronavirus Disease 2019; 2020. Available from: https:// www.medrxiv.org/content/10.1101/2020.03.05.2003050 2v1. [Last accesed on $2020 \mathrm{Apr} 19]$.

22. Klompas M, Morris C, Sinclair J, Pearson M, Shenoy E. Universal masking in hospitals in the COVID-19 era. $\mathrm{N}$ Engl J Med. 2020;382:970-1.

23. World Health Organization. Advice on the Use of Masks in the Context of COVID-19. Geneva: World Health Organization; 2020. p. 1-2.

24. Feng S, Shen C, Xia N, Song W, Fan M, Cowling BJ. Rational use of face masks in the COVID-19 pandemic. Lancet Respir Med. 2020;2:2019-20

25. Secretaría de Salud. Manejo de los cubrebocas/máscaras o respiradores N95. In: Proceso de Prevención de Infecciones Para las Personas con Covid-19 Contactos y Personal de la Salud. Mexico: Gobierno de México, Secretaría de Salud; 2020. p. 13-21.

26. National Center for Immunization and Respiratory Diseases (NCIRD), Division of Viral Diseases. Use Cloth Face Coverings to Help Slow Spread. CDC. Available from: https://www.cdc.gov/ coronavirus/2019-ncov/prevent-getting-sick/diy-cloth-facecoverings.html. [Last accesed on $2020 \mathrm{Apr} 22$ ].

27. Greenhalgh T, Schmid MB, Czypionka T, Bassler D, Gruer L. Face masks for the public during the covid-19 crisis. BMJ. 2020;369:1-4.

28. Guyatt GH, Oxman AD, Kunz R, Woodcock J, Brozek J, Helfand $M$, et al. GRADE guidelines: 8 . Rating the quality of evidenceindirectness. J Clin Epidemiol. 2011;64:1303-10.

29. Bartoszko JJ, Farooqi MA, Alhazzani W, Loeb M. Medical masks vs N95 respirators for preventing COVID-19 in health care workers a systematic review and meta-analysis of randomized trials. Influenza Other Respi Viruses. 2020; [Epub ahead of print].

30. Brainard JS, Jones N, Lake I, Hooper L, Hunter P. Facemasks and Similar Barriers to Prevent Respiratory Illness Such as COVID-19. a Rapid Systematic Review; 2020. Available from: https://www. medrxiv.org/content/10.1101/2020.04.01.20049528v1. [Last accesed on $2020 \mathrm{Apr} 22$ ]

31. Stern D, López-olmedo N, Pérez-ferrer C, González-Morales R Canto-Osorio F, Barrientos-Gutiérrez T. Revisión rápida del uso 
de cubrebocas quirúrgicos en ámbito comunitario e infecciones respiratorias agudas. Salud Publica Mex. 2020;3:1-12.

32. Jefferson T, Jones MA, Al-Ansary LA, Bawazeer GA, Beller E, Clark J, et al. Physical Interventions to Interrupt or Reduce the Spread of Respiratory Viruses. Part 1-face Masks, Eye Protection and Person Distancing: systematic Review and Meta-analysis Jefferson; 2020. Available from: https://www.medrxiv.org/con tent/10.1101/2020.03.30.20047217v2. [Last accesed on 2020 Apr 23].

33. Jefferson T, Del Mar CB, Dooley L, Ferroni E, Al-Ansary LA, Bawazeer GA, et al. Physical interventions to interrupt or reduce the spread of respiratory viruses. Cochrane database Syst Rev. 2011;7:CD006207.

34. World Health Organization. Physical interventions to interrupt or reduce the spread of respiratory viruses. In: Infection Prevention and Control of Epidemic-and Pandemic-prone Acute Respiratory Infections in Health Care. Geneva: World Health Organization; 2014. p. 98-107.

35. Norris SL, Gollogly L, Penn C, Al-Shorbaji N, Momen H. Evidence retrieval and synthesis. In: WHO Handbook for Guideline Development. Ch. 8. Geneva: World Health Organization; 2014 p. 93-108.

36. Leung NH, Chu DK, Shiu EY, Chan KH, McDevitt JJ, Hau BJ, et al. Respiratory virus shedding in exhaled breath and efficacy of face masks. Nat Med. 2020;2020:1-5.

37. Javid B, Weekes MP, Matheson NJ. Covid-19: should the public wear face masks? BMJ. 2020;369:m1442.

38. Maclntyre CR, Seale H, Dung TC, Hien NT, Nga PT, Chughtai AA, et al. A cluster randomised trial of cloth masks compared with medical masks in healthcare workers. BMJ Open. 2015;5:1-10.

39. Fineberg HV. Rapid Expert Consultation on the Effectiveness of Fabric Masks for the COVID-19 Pandemic. Washington, DC: The
National Academies Press; 2020. Available from: http://www. nap.edu/25776. [Last accesed on $2020 \mathrm{Apr} 22$ ].

40. Shakya KM, Noyes A, Kallin R, Peltier RE. Evaluating the efficacy of cloth facemasks in reducing particulate matter exposure. Exp Sci Environ Epidemiol. 2017;27:352-7

41. Davies A, Thompson KA, Giri K, Kafatos G, Walker J, Bennett A Testing the efficacy of homemade masks: would they protect in an influenza pandemic? Disaster Med Public Health Prep. 2013;7:413-8.

42. Bae S, Kim MC, Kim JY, Cha HH, Lim JS, Jung J, et al. Effectiveness of surgical and cotton masks in blocking SARS-CoV-2: a controlled comparison in 4 patients. Ann Intern Med. 2020; [Epub ahead of print].

43. Maclntyre CR, Cauchemez S, Dwyer DE, Seale $H$, Cheung $P$, Browne $\mathrm{G}$, et al. Face mask use and control of respiratory virus transmission in households. Emerg Infect Dis. 2009;15:233-41.

44. Maclntyre CR, Chughtai AA. Facemasks for the prevention of infection in healthcare and community settings. BMJ. 2015;350:1-12.

45. Howard J, Huang A, Li Z, Tufekci Z, Zdimal V, Van Der Westhuizen H. Face Masks Against COVID-19: an Evidence Review. Preprints; 2020. Available from: https://www.preprints.org/manuscript/202004.0203/v1. [Last accesed on 2020 Apr 23].

46. Tian L, Li X, Qi F, Tang QY, Tang V, Liu J, Li Z, et al. Calibrated Intervention and Containment of the COVID-19 Pandemic Populations and Evolution; 2020. Available from: http://www. arxiv:2003.07353. [Last accesed on 2020 Apr 23].

47. Biggerstaff M, Cauchemez S, Reed C, Gambhir M, Finelli L. Estimates of the reproduction number for seasonal, pandemic, and zoonotic influenza: a systematic review of the literature. BMC Infect Dis. 2014:14:1-20. 